\title{
Aplicaciones cartográficas en PEMEX
}

\author{
Margarita Jordá Lozano* \\ Miguel Zúñiga Montalvo**
}

\begin{abstract}
Description of the use of cartographic materials in Petróleos Mexicanos (PEMEX), from information, maps and institutional geographic information systems, highlight the most important applications today.
\end{abstract}

Key words: PEMEX, Cartography, Maps, Geographic Information Systems.

\section{Resumen}

Descripción del uso de los materiales cartográficos en Petróleos Mexicanos (PEMEX), a partir de la información, los mapas y los sistemas de información geográfica institucionales, destacando las aplicaciones más importantes actualmente.

Palabras clave: PEMEX, Cartografia, mapas, Sistemas de Información Geográfica.

\section{Antecedentes}

La cartografía se ha utilizado en la industria petrolera desde sus inicios como en cualquier otra actividad económica, para la ubicación de las materias primas, los medios de producción y las áreas consumidoras. Desde antes de la expropiación petrolera en México, se utilizaron planos para la localización de los campos petroleros, las instalaciones industriales y las ciudades más importantes.

Después de constituido Petróleos Mexicanos (PEMEX) en 1938, se utilizaron los planos petroleros existentes que tenían sistemas de coordenadas diferentes. Con el tiempo estos sistemas tuvieron que ser integrados para hacer los planos comparables. Para solucionar esta problemática durante la década de los cincuenta se reali-

* Subgerente de Sistemas de Información Geográfica de PEMEX DCTIPN, Plaza Polanco, Torre B, piso 4, México, D.F., correo electrónico: margarita.jorda@pemex.com

* Especialista en Información Geográfica, Subgerencia de Sistemas de Información Geográfica de PEMEX DCTIPN, Plaza Polanco, Torre B, piso 4, México, D.F., correo electrónico: miguel.zuniga@pemex.com 
zaron reuniones con autoridades cartográficas del gobierno y de instituciones académicas.

A finales de la década de los sesenta PEMEX crea el Departamento de Cartografía y Geodesia que con apoyo del Servicio Cartográfico Militar, avanza en el ajuste de los planos a la proyección UTM (Universal Transversa de Mercator). Como resultado, estos materiales se empiezan a utilizar en más actividades petroleras.

Así, conforme se desarrolló la industria petrolera nacional, el uso de la información cartográfica se incrementó hasta ser un sustento técnico de actividades como la exploración, la perforación y el transporte y distribución de petrolíferos.

Durante la década de los ochenta, a la par de que la información geográfica cobraba más relevancia en la industria petrolera nacional e internacional, se usaron en PEMEX además de los planos petroleros, las cartas topográficas escala 1:1,000,000 y 1:250,000 del Instituto Nacional de Estadística y Geografía (INEGI) para apoyar las actividades petroleras.

A partir de la década de los noventa con el desarrollo acelerado de los sistemas de información geográfica en el mundo, las áreas técnicas de PEMEX que usaban planos y cartas empiezan a ver los sistemas geográficos como una opción para obtener y generar planos y mapas de manera más ágil.

En 1991 a partir de un convenio de colaboración técnica INEGI-PEMEX, se escanearon con un alto control de calidad las cartas topográficas escala 1:1,000,000 y 1:250,000 en sus cuatro positivos de impresión, y por primera vez en México se tuvo una cartografía digital de todo el territorio nacional. En ese momento se inició en PEMEX la creación del Sistema de Información Geográfica de la Industria Petrolera.

Además de este sistema que permanece hasta la fecha y que es representativo por el alto número de áreas que atiende, existen actualmente aplicaciones que cubren los requerimientos de las áreas operativas en las regiones petroleras del país, y que apoyan directamente las actividades de exploración, extracción, producción, logística, protección ambiental, transporte de petrolíferos e hidrocarburos, refinación, producción de gas y seguridad industrial, entre otros temas.

A partir de 2010 gran parte de los sistemas geográficos de PEMEX fueron integrados por la creación de la Dirección Corporativa de Tecnología de Información y Procesos de Negocio, que ahora concentra todas las áreas de tecnología de información de la empresa, tanto las que pertenecieron al corporativo como las de sus cuatro organismos subsidiarios: Pemex Exploración y Producción, Pemex Refinación, Pemex Gas y Petroquímica Básica y PEMEX Petroquímica.

El objetivo de esta integración es fortalecer el Sistema de Información Geográfica de la Industria Petrolera, a partir de un banco central de datos geoespaciales con las diferentes aplicaciones existentes, homologando las plataformas tecnológicas de acuerdo a los estándares del Open Geospatial Consortium (OGC). 


\section{Subgerencia de Sistemas de Información Geográfica de PEMEX}

La Subgerencia de Sistemas de Información Geográfica, dependiente de la Gerencia de Servicios Técnicos Especializados, de la Subdirección de Integración de Soluciones y Procesos de Negocio y de la Dirección Corporativa de Tecnología de Información y Procesos de Negocio de PEMEX, es el área que se encarga de consolidar y proporcionar las soluciones y servicios de información geoespacial que contribuyan al desarrollo de los procesos sustantivos y operativos de PEMEX y sus organismos subsidiarios.

También tiene la responsabilidad de realizar con organismos públicos y privados la suscripción de convenios de colaboración técnica e intercambio de información en materia geoespacial, respetando la normatividad y los estándares a nivel nacional e internacional.

Esta Subgerencia opera con tres aspectos destacados que la hacen especial no sólo dentro de PEMEX, sino incluso dentro de la administración pública federal:

- Esta área se maneja como una unidad de negocio, con un sistema de facturación a partir del cual se distribuyen productos y servicios cartográficos al interior de PEMEX. Esto permite tener niveles de comparación con los costos de estos productos y servicios en el mercado, para evaluar la productividad y eficiencia de los recursos invertidos en la Subgerencia.

- Opera bajo el esquema de un sistema de gestión de calidad basado en procesos, que rige a todas las áreas tanto técnicas como administrativas y que ha permito contar con una certificación ISO (International Organization for Standardization) de calidad desde 1998.

- La base de datos geográfica y los servicios que ofrece son conformes con los estándares y las implementaciones del OGC (Open Geospatial Consortium), organismo internacional responsable de estandarizar aspectos en el ámbito geoespacial.

La Subgerencia está integrada por tres superintendencias, que en términos generales son: proyectos, información y servicios. Los temas más destacados en la cartera de servicios geoespaciales de la Subgerencia son los siguientes:

- Elaboración e impresión de planos y mapas con información petrolera y con información geográfica del entorno de las instalaciones.

- Proporcionar acceso a las bases de datos institucionales por medio de diferentes plataformas y aplicaciones cartográficas.

- Desarrollo de servicios geográficos Web, como WMS (Web Map Service), WFS (Web Feature Service) y WCS (Web Coverage Service). 
- Análisis geoespacial de datos sociales, económicos y demográficos de las áreas en el entorno de las instalaciones petroleras.

- Generación de modelos digitales del terreno y superficie y, análisis de los mismos vía perfiles topográficos, curvas de nivel, mapas de declives y líneas de vista.

- Clasificaciones supervisadas y no supervisadas de fenómenos físicos y sociales en el entorno de las instalaciones petroleras vía imágenes de satélite.

- Levantamientos de información geográfica dentro y en el entorno de las instalaciones petroleras.

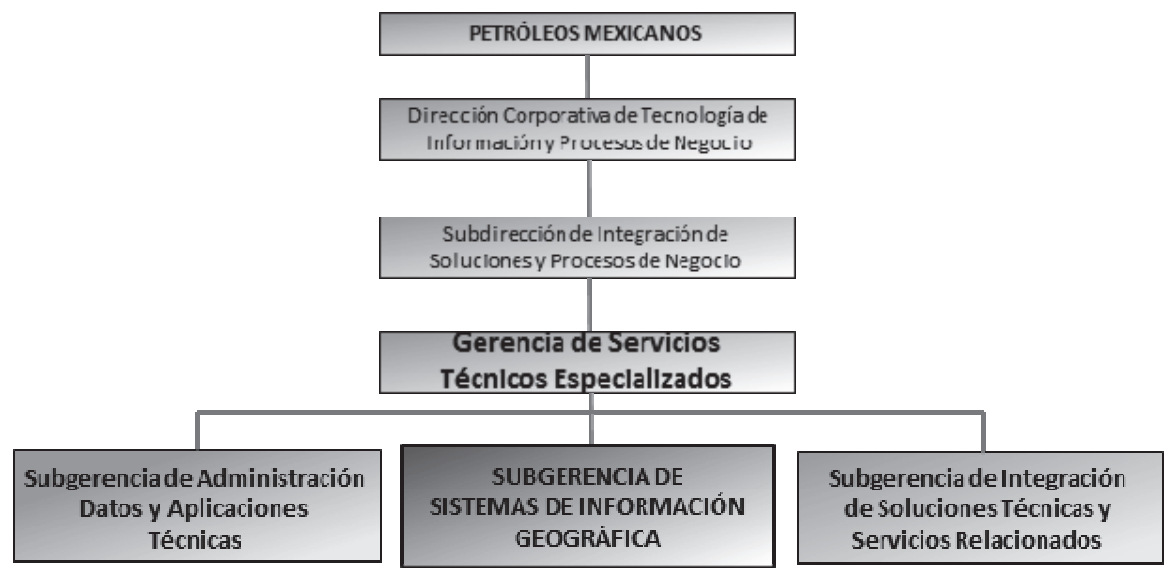

Figura 1. Estructura orgánica de la Subgerencia de Sistemas de Información Geográfica de PEMEX.

Los principales grupos de datos petroleros con los que la Subgerencia de Sistemas de Información Geográfica proporciona sus servicios son los siguientes:

- Seis refinerías

- Ocho complejos petroquímicos

- 10 centros procesadores de gas

- 16 terminales de distribución de gas licuado

- 77 terminales de almacenamiento y reparto

- 1,323 instalaciones estratégicas

- 10,140 estaciones de servicio - gasolineras

- Pozos petroleros, con alrededor de 32,000 de ellos

- Red nacional de derechos de vía de PEMEX, con $60,568 \mathrm{~km}$ de ductos de transporte de hidrocarburos

- Asignaciones petroleras — división territorial para la actividad petrolera 
- Activos y campos petroleros - áreas de extracción y producción

- Oportunidades de exploración — puntos en los que se explora

- Inventario nacional de proyectos de exploración, perforación y extracción

- Peras y macro peras de los pozos petroleros - área de maniobras

- Investigación sísmica para exploración en dos y tres dimensiones

- Geología petrolera, provincias geológicas y cuencas terciarias y mesozoicas

- Planos detallados de las instalaciones petroleras más importantes

- Modelos tridimensionales de las principales instalaciones petroleras

- Fotografías oblicuas del interior de las principales instalaciones petroleras

- Fotografías de $360^{\circ}$ del interior de las principales instalaciones petroleras

- Puntos de control geodésico en las principales instalaciones petroleras

- Modelos digitales de terreno de las principales instalaciones petroleras

- Planos de administración patrimonial — terrenos, construcciones, edificaciones e instalaciones de PEMEX

- Fugas y derrames en la red de ductos de transporte de PEMEX

- Inventario de tomas clandestinas en la red de ductos de transporte de PEMEX

- Manifestaciones y actos vandálicos en el entorno de las instalaciones petroleras

Los principales grupos de datos temáticos del entorno con los que la Subgerencia de Sistemas de Información Geográfica proporciona sus servicios son los siguientes:

- Cartografía topográfica escala 1:1,000,000 del Instituto Nacional de Estadística y Geografía (INEGI)

- Cartografía climática escala 1:500,000 del INEGI

- Cartografía topográfica escala 1:400,000 de la empresa Sistemas de Información Geográfica S.A. (SIGSA)

- Cartografía topográfica escala 1:250,000 del INEGI

- Batimetría del Golfo de México escala 1:250,000 del INEGI-IBCCA

- Cartografía geológica escala 1:250,000 del INEGI

- Cartografía de uso del suelo escala 1:250,000 del INEGI

- Cartografía topográfica escala 1:200,000 de SIGSA

- Cartografía topográfica escala 1:100,000 de la Secretaría de la Defensa Nacional (SEDENA)

- Cartografía topográfica escala 1:50,000 del INEGI

- Cartografía topográfica escala 1:40,000 de SIGSA

- Cartografía topográfica escala 1:20,000 del INEGI y de SIGSA

- Cartografía topográfica escala 1:15,000 del Valle de México de la SEDENA

- Cartografía topográfica escala 1:5,000 de SIGSA

- Cartografía Urbana 2000 del INEGI 
- Marco geo estadístico 2000, 2005 y 2010 del INEGI país, estados, municipios, localidades urbanas y localidades rurales

- Cartografía geo estadística 2000, 2005 y 2010 del INEGI

- Censos de Población y Vivienda 2000 y 2010 del INEGI

- Conteo de Población 2005 del INEGI

- Áreas Geo Estadísticas Básicas (AGEB) 2010 del INEGI

- Directorio Estadístico Nacional de Unidades Económicas (DENUE) 2012 del INEGI

- Localidades urbanas con números exteriores 2010 del INEGI

- Redes hidrológicas con conectividad escala 1:250,000 y escala 1:50,000 del INEGI

- Servicio Web de imágenes QuickBird y WorldView I (Global Base Map) del territorio nacional, proporcionado por la empresa DigitalGlobe

- Servicios Web de PEMEX con la red carretera nacional y con la red nacional de calles de las zonas urbanas, con datos de la empresa HERE, antes NavTeq

- Modelo de elevación Shuttle Radar Topography Mission (SRTM) de 30 y $90 \mathrm{~m}$

- Modelo de elevación Advanced Spaceborne Thermal Emission and Reflection Radiometer (ASTER) de 30m

- Continúo de Elevación Nacional de 30m del INEGI

- Estructura ejidal nacional y lotes rurales certificados en el Programa de Certificación de Derechos Ejidales y Titulación de Solares (PROCEDE) 2010

- Polígonos de las zonas militares de la SEDENA

- Imágenes de satélite IRS, Landsat, Spot, Ikonos, QuickBird, WorldView I y GeoEye 1

- Fotografías aéreas y orto fotos digitales desde $1 \mathrm{~m}$ hasta $10 \mathrm{~cm}$ de resolución

Actualmente los usuarios de la Subgerencia se integran por los que solicitan mapas específicos, los que usan los servicios Web y los que tienen acceso a las aplicaciones cartográficas en línea, según la siguiente estructura por organismo subsidiario de PEMEX:

- PEMEX Exploración y Producción concentra el 38\%

- Las áreas corporativas concentran el $24 \%$

- PEMEX Refinación concentra el 19\%

- PEMEX Gas y Petroquímica Básica concentra el $13 \%$

- PEMEX Petroquímica concentra el 6\%

Entre las acciones que la Subgerencia ha implementado con instituciones externas destacan los intercambios de información, experiencia y apoyo técnico en materia cartográfica, de información y de sistemas geográficos con las siguientes dependencias gubernamentales: 


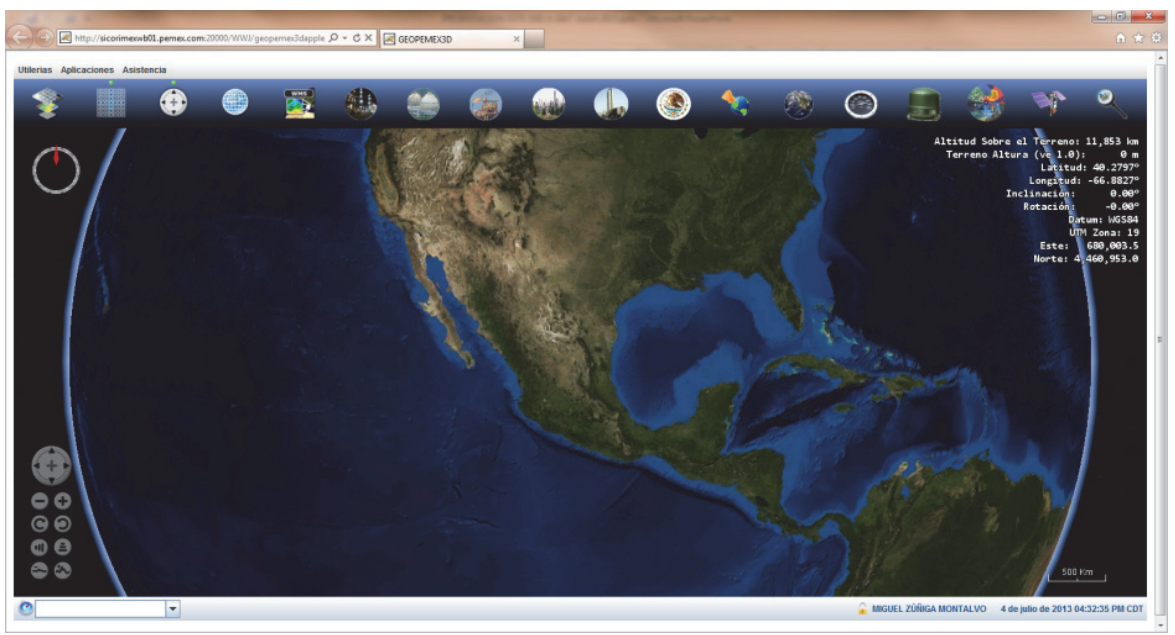

Figura 2. Plataforma cartográfica GeoPEMEX 3D. Aquí se muestra la pantalla inicial, que destaca el globo terráqueo, el menú colgante, los controles de vista abajo a la izquierda y arriba a la derecha, la información de los sistemas de coordenadas, la altura de la vista y la altitud del terreno.

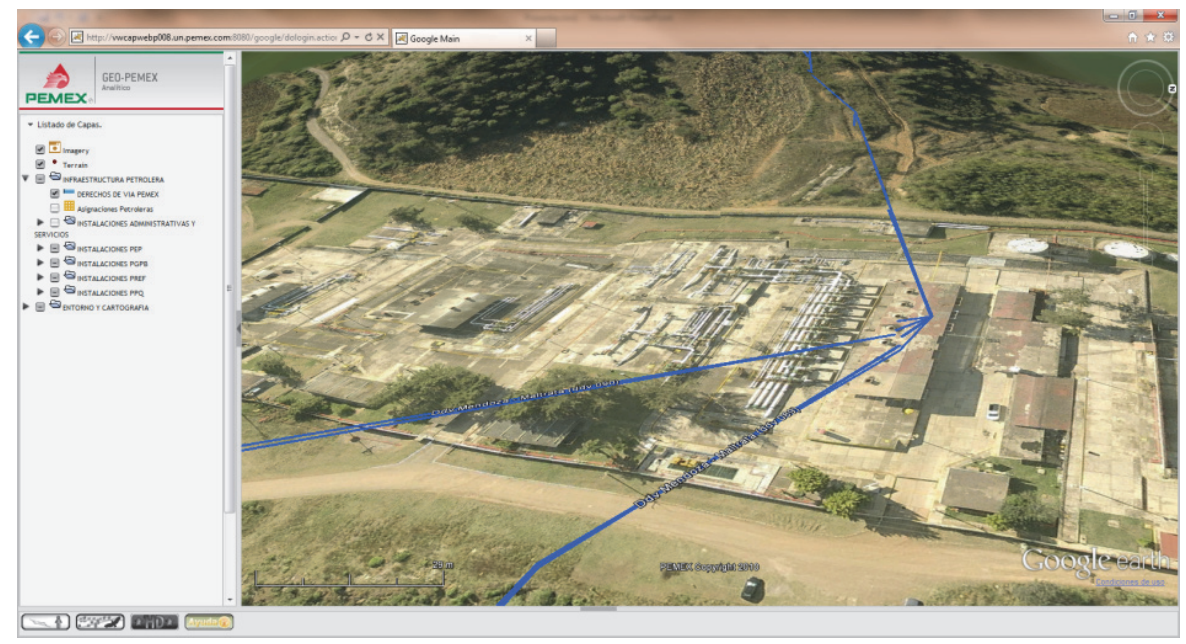

Figura 3. Plataforma cartográfica GeoPEMEX 3D Analítico. Aquí se muestra un acercamiento a una estación de bombeo, vista con ortofoto de $10 \mathrm{~cm}$ de resolución, en la que se aprecia el relieve terrestre y las líneas que representan los derechos de vía por donde corren los ductos de transporte. Al lado izquierdo se aprecia el árbol de capas y abajo botones para despliegue de determinados paquetes de datos. 


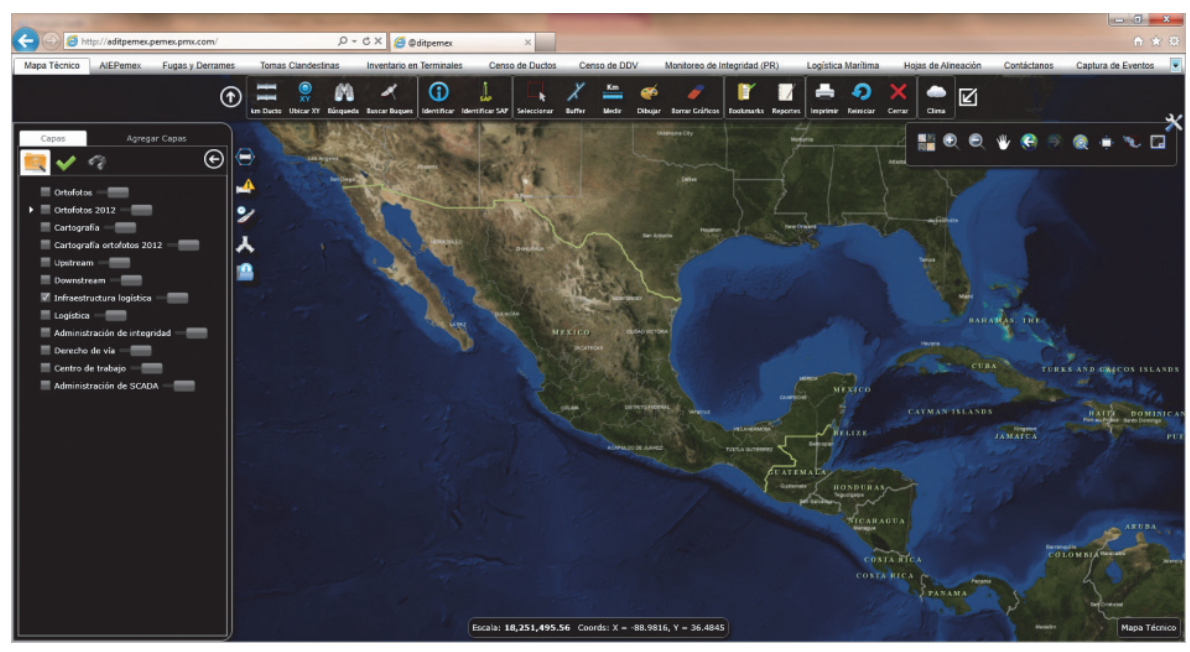

Figura 4. Plataforma @DIT a partir de la cual opera la aplicación cartográfica de la iniciativa@DITPEMEX desarrollada principalmente para las áreas técnicas corporativas de PEMEX. Aquí se muestra la pantalla inicial, dónde se pueden apreciar arriba las pestañas temáticas, el árbol de capas a la izquierda y los controles de vista, medición y análisis geográfico arriba y a la derecha.

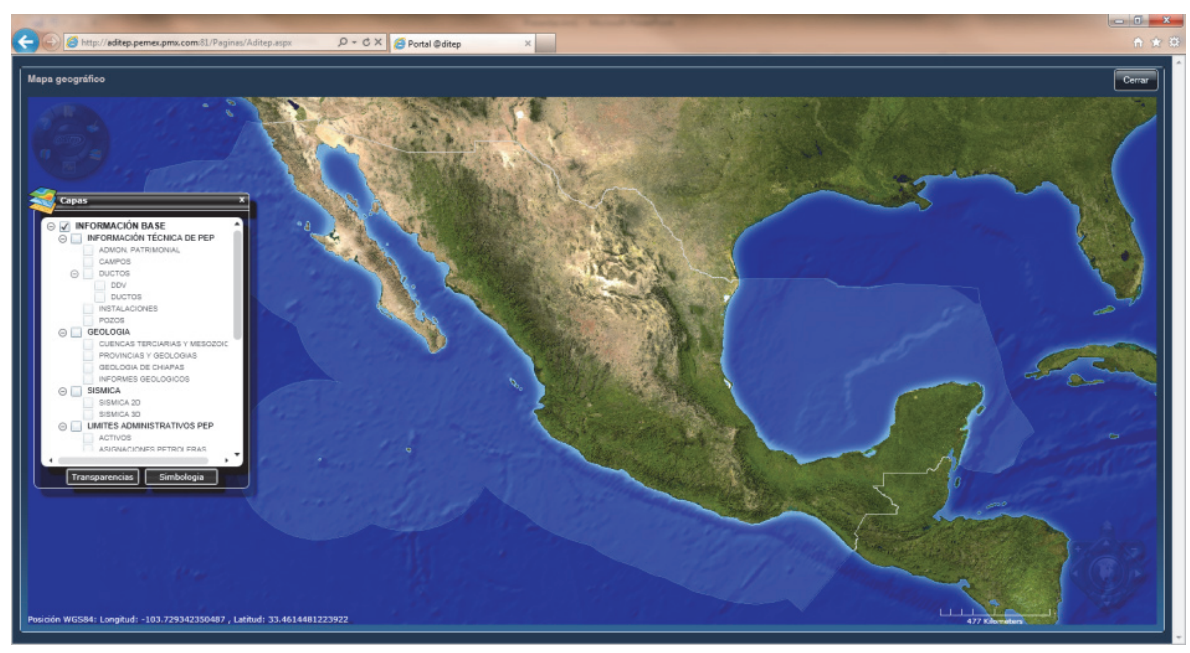

Figura 5. Plataforma @DIT a partir de la cual opera la aplicación cartográfica de la estrategia@DITEP, desarrollada para las áreas técnicas de Pemex Exploración y Producción. Aquí se muestra la pantalla inicial, dónde se destaca arriba a la izquierda transparente el menú de funciones el árbol de capas, abajo a la derecha los controles de vista también transparentes. 
- Instituto Nacional de Estadística y Geografía ( INEGI)

- Secretaría de Energía (SENER)

- Comisión Federal de Electricidad (CFE)

- Secretaría de Marina (SEMAR)

- Secretaría de la Defensa Nacional (SEDENA)

- Secretaría del Medio Ambiente y Recursos Naturales (SEMARNAT)

- Secretaría de Comunicaciones y Transportes (SCT)

- Secretaría de Gobernación (SG)

- Secretaría de Educación Pública (SEP)

- Comisión Nacional del Agua (CONAGUA)

- Registro Agrario Nacional (RAN)

- Servicio Geológico Mexicano (SGM)

- Instituto Mexicano del Trasporte (IMT)

\section{Plataformas tecnológicas y aplicaciones cartográficas}

Una de las plataformas tecnológicas más importantes que ahora opera en PEMEX es GeoPEMEX 3D, sistema en tres dimensiones, que inició operaciones en 2006 y que fue desarrollado por personal de PEMEX.

Esta plataforma además de contar con un paquete básico de funciones e información petrolera y geográfica de uso común, destaca por haberse desarrollado sobre ella una aplicación que rastrea barcos petroleros a nivel mundial, con la que se pueden ubicar alrededor de 12,000 embarcaciones vía sus sistemas de navegación GPS (Global Positioning System). Esta información resulta esencial y estratégica en la carga y descarga de petrolíferos, ya que permite a PEMEX obtener ahorros sustanciales en sus operaciones marítimas.

Esta plataforma requiere la instalación de un programa previo para su operación y es capaz de desplegar un gran número de capas, debido a su flexibilidad de obtener información a partir de bases de datos comerciales y de servicios Web.

La nueva plataforma tecnológica que es una versión desarrollada y evolucionada del GeoPEMEX 3D, empezó a funcionar en el año 2010, se llama GeoPEMEX 3D Analítico, también muestra datos en tres dimensiones, se alimenta con un servidor de mapas propietario y opera sobre el navegador de Internet.

El objetivo de esta plataforma fue el proporcionar al usuario una base geográfica en tres dimensiones, en la que se pudiera incorporar gran cantidad de la información cartográfica que se requiere para el desarrollo de las funciones en muchas áreas de PEMEX. Ahora su visualizador despliega una infinidad de capas geográficas, incluso muchas de las que se visualizan en otras plataformas.

La siguiente plataforma cartográfica @DIT, nombrada así por su función de integrar datos e información técnica, opera en dos dimensiones y actualmente se le ha incorporado funcionalidad adicional a la básica, como consulta de bases de datos 
externas, análisis geográficos, generación de gráficas y ligas en línea con sistemas técnicos y financieros de PEMEX.

La plataforma se alimenta con su propia base de datos espacial y opera sobre el navegador de Internet. Hasta ahora se han desarrollado dos aplicaciones cartográficas que apoyan a departamentos técnicos de PEMEX, una es el visualizador geográfico de la iniciativa@DITPEMEX, que integra un banco de datos para apoyar a las áreas técnicas de la Dirección Corporativa de Operaciones de PEMEX.

La otra aplicación desarrollada con base en la plataforma@DIT, es el componente cartográfico de la iniciativa @DITEP, que es una estrategia para la integración de un banco de datos en apoyo de las actividades de PEMEX Exploración y Producción. Esta aplicación además de contar con las funciones tradicionales, cuenta con un completo paquete de análisis geográfico y generación de consultas y reportes.

Las aplicaciones cartográficas son los programas o sistemas desarrollados a partir de las plataformas tecnológicas, que son diseñados, configurados y administrados en función de las necesidades de información geográfica de los usuarios.

Una aplicación cartográfica busca proporcionar la información necesaria en el momento preciso, con objeto que el usuario disponga de elementos que le permitan tomar decisiones para el mejor desarrollo de los procesos sustantivos de la empresa, como: la exploración, la perforación, la extracción, la producción, el transporte, la refinación y la distribución de hidrocarburos.

En los últimos tres años se han desarrollado varias aplicaciones cartográficas con base en la plataforma GeoPEMEX 3D Analítico, entre las que destacan el sistema de catastro petrolero o de administración patrimonial, el sistema de áreas de influencia y generación de rutas de traslado terrestre para la distribución de gas licuado, el sistema administrador de franquicias de estaciones de servicio (gasolineras) y el sistema para la ubicación de servicios médicos alternos para los empleados de PEMEX.

En apoyo a otras aplicaciones cartográficas, se le han incorporado datos nuevos a la plataforma GeoPEMEX 3D Analítico, como modelos industriales en tres dimensiones, fotografías oblicuas, fotografías terrenas de $360^{\circ}$, ortofotos de $10 \mathrm{~cm}$ de resolución y el modelo de elevación ASTER de 30m de resolución.

Las aplicaciones cartográficas sobre la plataforma@DIT también han experimentado mejoras considerables en los últimos años, a la aplicación cartográfica de la iniciativa@DITEP, se le incorporó la siguiente funcionalidad:

- Generación de perfiles topográficos

- Carga de archivos en formato geográfico (extensión .shp)

- Búsquedas complejas, dónde se incorporan varias condiciones geográficas, como dentro de este campo petrolero o en las cercanías de esta localidad

- Generación de áreas de influencia por medio de líneas o puntos (áreas buffer) 


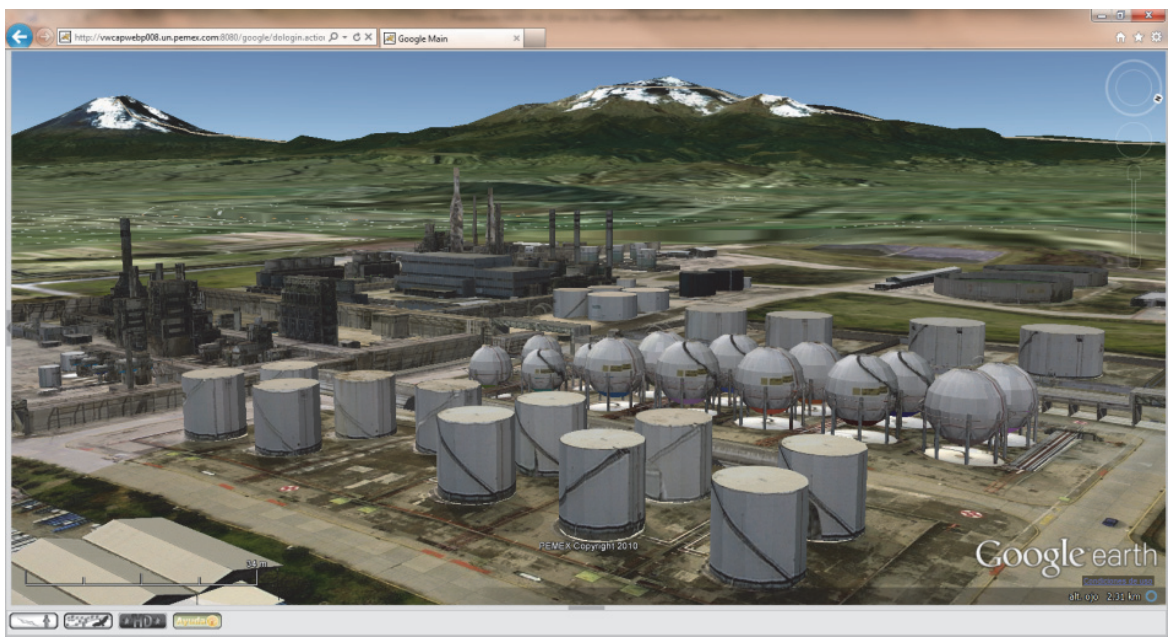

Figura 6. Modelos tridimensionales en la plataforma cartográfica GeoPEMEX 3D Analítico. Aquí se muestra un acercamiento al área de tanques y esferas del Complejo Petroquímico Independencia, en San Martín Texmelucan, Puebla. Al fondo se aprecian los volcanes del Valle de México, representados por medio del modelo de elevación ASTER de 30m de resolución.

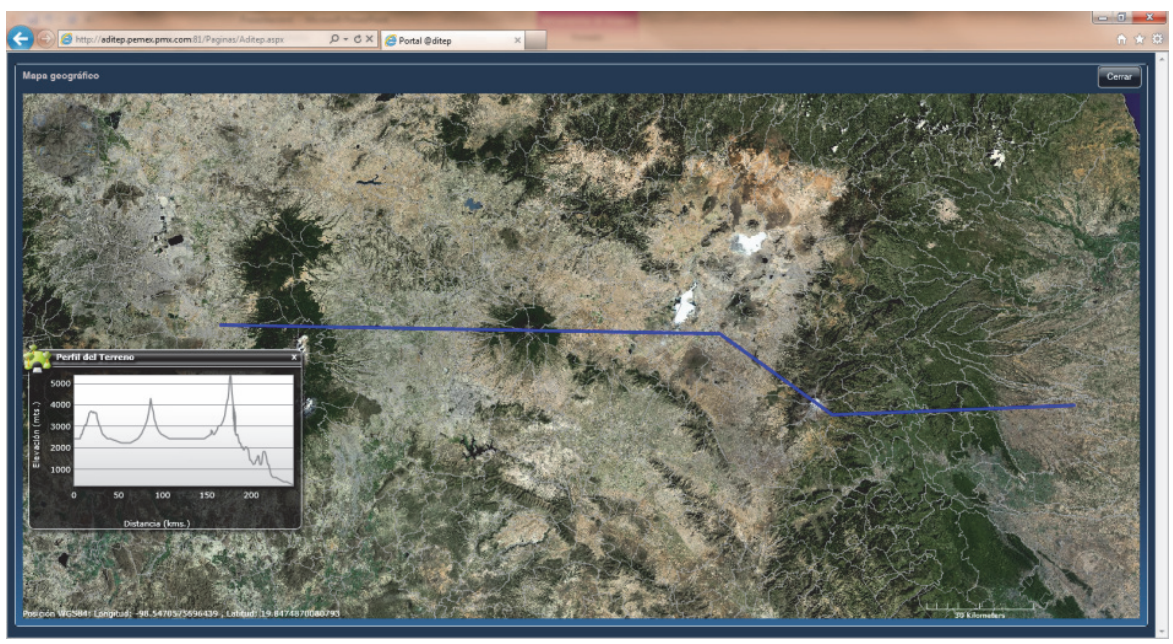

Figura 7. Perfil topográfico desde el Valle de México hasta la llanura costera veracruzana, pasando por las faldas del Iztaccíhuatl, por la Malinche y por el Pico de Orizaba, generado con el componente cartográfico de la estrategia @DITEP, desarrollado para Pemex Exploración y Producción. En el recuadro abajo a la izquierda, se aprecia el perfil topográfico, en la vertical la altitud y en la horizontal la longitud. 
A la aplicación cartográfica @DITPEMEX, se le adicionaron las siguientes mejoras:

- Información de fugas y derrames en los ductos y en las instalaciones petroleras

- Censo de ductos de transporte de PEMEX

- Listado de tomas clandestinas sobre la red de ductos de PEMEX

- Búsqueda y localización de buques tanque de PEMEX

- Componente de logística marina, que apoya las operaciones portuarias de PEMEX

Un tema al cual se le pone especial atención en el desarrollo de aplicaciones cartográficas, es el de los datos con los que va a operar el sistema, ya que con mucha frecuencia éstos requieren gran inversión de recursos.

Por lo general la información para la operación de las aplicaciones cartográficas proviene de las áreas usuarias que son propietarias y autoras de los datos, pero en otras ocasiones esta información debe obtenerse de otras áreas de PEMEX, de instituciones gubernamentales externas o incluso debe levantarse porque no existe.

Uno de los principios con los que se desarrollan actualmente las aplicaciones cartográficas en PEMEX, es que las áreas usuarias, propietarias y autoras de los datos, sean las responsables de administrarlos y actualizarlos, para esto se desarrollan menús para cargar, modificar y borrar información.

Un punto a destacar con respecto a las funciones de las aplicaciones cartográficas, es que gran parte de ellas se incorporan conforme el usuario las solicita. En un principio se configura un paquete básico acordado en el diseño y planeación de la aplicación. Las nuevas funciones se complementan cuando los usuarios sustituyen sus procesos tradicionales por nuevos procesos basados en el sistema.

El primer paso para desarrollar una aplicación cartográfica, es identificar un requerimiento de información y confirmar que la plataforma seleccionada cubra las necesidades de funcionalidad y análisis; y el segundo, es diseñar y planear el desarrollo de la aplicación en conjunto con los usuarios del área solicitante.

El desarrollo de una aplicación cartográfica implica básicamente dos líneas de trabajo, por un lado, la configuración de la plataforma con la imagen institucional, los menús necesarios, las funciones específicas y los análisis geográficos y; por el otro, la integración de las capas geográficas que permitirán que la aplicación lleve a cabo las funciones para las que fue creada.

\section{Próximas acciones}

- Fortalecer y ampliar los convenios de colaboración técnica e intercambio de experiencias e información geográfica.

- Mejorar el papel de proveedor de servicios geoespaciales con las áreas usuarias. 
- Continuar con la integración del banco central de datos geoespaciales para fortalecer el Sistema de Información Geográfica de la Industria Petrolera.

- Homologar las plataformas tecnológicas existentes para mejorar el desarrollo de las aplicaciones cartográficas institucionales.

- Continuar con el levantamiento de modelos tridimensionales, ortofotos y fotografías $360^{\circ}$ de las instalaciones petroleras estratégicas.

\section{Bibliografía}

Álvarez, J. (2006). "Crónica del petróleo en México. De 1863 a nuestros días", Petróleos Mexicanos, Distrito Federal, México.

Caire, J. (2002). Cartografía Básica, Editorial de la Facultad de Filosofía y Letras, UNAM, México, D.F.

Conesa, C. y Martínez, J. B. (2004). Territorio y medio ambiente: métodos cuantitativos y técnicas de información geográfica, Edición Universidad de Murcia, España.

Joly, F. (1982). La Cartografia, traducción de Julio Morencos Tevar, Editorial Ariel, Barcelona, España.

PEMEX, Subgerencia de Sistemas de Información Geográfica (2004). "Política General de Información Geográfica de Petróleos Mexicanos y Organismos Subsidiarios", documento en normateca institucional, Distrito Federal, México.

— Subgerencia de Sistemas de Información Geográfica (2010). "Manual de Organización de la Subgerencia de Sistemas de Información Geográfica", documento normativo interno, Distrito Federal, México.

— Subgerencia de Sistemas de Información Geográfica (2010). "Manual de Procedimientos de la Subgerencia de Sistemas de Información Geográfica", documento normativo interno, Distrito Federal, México.

Pérez, C. y Muñoz, A. L. (2006). Teledetección, nociones y aplicaciones, Editorial de la Universidad de Salamanca, España.

Valdez, M. E. y Franco, S. (2003). "Principios Básicos de Cartografía y Cartografía Automatizada", Editorial de la Universidad Autónoma del Estado de México, Toluca, México. 